\title{
OUTCOME OF ENDOSCOPIC DCR AT TUTH
}

\section{B. Pradhan}

Ganesh Man Singh Memorial Academy of ENT and Head \& Neck Studies T U-Teaching Hospital, Maharajgung, Kathmandu, Nepal.

\section{Correspondence to:}

Prof. Bibhu Pradhan

Unit Chief, Rhinology Unit

Ganesh Man Singh Bhawan

TU Teaching Hospital, Maharajgunj, Kathmandu, Nepal

E-mail: bibhuduga@yahoo.com
Objective:

The objective of this study was to find the outcome of endoscopic DCR (EDCR) and to find the factors causing failure of EDCR

Material and methods:

A prospective, longitidunal study including 75 patient diagnosed case of chronic dacryocystitis was carried out at Ganesh Man Singh Memorial Academy (GMSMA) of ENT and HN studies, Institute of Medicine (IOM), Maharajgunj, Kathmandu from march 2005 to feb 2011.

Results:

Out of 75 patient, 35 were male and 40 were female, the age ranged from 18 to 60 years. After one year of follow-up post surgery, 7 patient had recurrence of epiphora. In 5 cases it was due to synechiae formation and in two cases due to upper lacrimal pathway obstruction.

Conclusion:

Endoscopic DCR is simple, safe and effective method to treat chronic dacryocystitis. Correction of nasal pathway should be done either before or during surgery to increase the sucess rate .

Key words: endoscopic DCR, dacryocystitis, complications.

\section{INTRODUCTION:}

Although the external DCR is thought to be gold standard for chronic dacryocystitis, EDCR is getting popular worldwide because of its many advantages.1 After the advent of nasal endoscopy, it became possible to approach the operation from nasal side, thereby avoiding facial scar and unnecessary dissection of orbicularis muscle and orbital periostium. External DCR was first proposed by Caldwell in 1893 and developed by West in 1910.2 In 1992, Mc Donogh performed first endoscopic transnasal DCR.3 After that, this procedure has been practiced by ENT surgeons of all over the world with some surgeons claiming success rate more than $90 \%$ in the experienced hand.

The reason behind publishing this article is, though EDCR is frequently done procedure in many countries and many articles have been published with high success rate of this procedure, but in Nepal this surgery is done in very few centres and no article has been published till date to our knowledge. All patients of chronic dacryocystitis cannot undergo EDCR; there are certain indications like distal obstruction in the lacrimal pathway and obstruction at the nasolacrimal duct, which is confirmed by simple test like eye irrigation and probe test. On irrigation, if there is reflux from the opposite punctum and on probe test if we find hard stop, these patients will be benefited from EDCR. Obstruction at the upper lacrimal pathway, which is confirmed by the probe test, if it shows soft stop or if we suspect neoplasm or dacryolithiasis, these cases are contraindicated for EDCR.4

There are many advantages to EDCR.4, 5 like no external scar, excellent visualization of intranasal structures, can be done at the same sitting, preserves the pumping mechanism of orbicularis oculi muscle, simultaneous nasal surgeries for other nasal pathologies are possible and minimal bleeding, so shorter operation time.

Causes of failure of external DCR reported in literature are: deviated nasal septum, chronic rhinosinusitis, presence of prominent agar nasi cells, small intranasal ostium and intranasal synechiae.6

\section{MATERIALS AND METHOD:}

This study was conducted at the Ganesh Man Singh Memorial Academy of ENT-Head and Neck Studies, TU- Teaching Hospital, Kathmandu, Nepal, from March 2005 to February 2011. Total number of 75 EDCR was performed during this period.
All 75 patients underwent EDCR under GA. Dilatation of punctum and probing was done to confirm the diagnosis. Local infiltration of $2 \%$ xylocain with adrenaline was injected at the axilla of middle turbinate. Incision was made anterior to uncinate process, mucoperiosteal flap was elevated posteriorly upto uncinate process, lacrimal bone was palpated and was removed by lacrimal punch or coarse diamond burr. It is important to remove bone superiorly upto common cannaliculus and inferiorly upto the nasolacrimal duct. The sac was made prominent by injecting little saline and it was opened from superior to inferior using sickle knife and with the help of ball probe. Adhesion inside the sac was released, anterior and posterior flap of the sac was reflected and abgel was kept in between the flaps. No packing was required. All patients were advised to have: Ciprofloxacin $500 \mathrm{mg}$ BD for10 days, lbuprofen $400 \mathrm{mg}$ TDS, after food, for three days. Steroid eye drop in tapering dose was given for one week and followed up as per our follow up criteria. All follow up were done with nasal endoscope which was done after one week to remove the blood clot and to release the adhesions if present.

RESULTS:

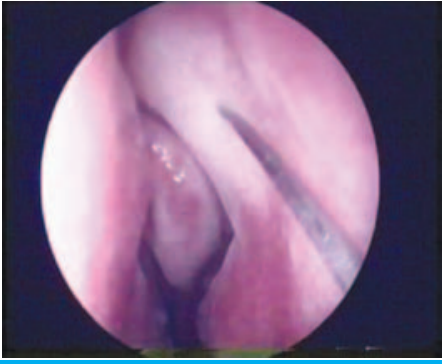

Fig: 1. showing endoscopic view of EDCR in progress

During our study, we analyzed not only the outcomes of EDCR and factors causing failure of EDCR but also analyzed nasal pathology of all patients during endoscopic evaluation prior to surgery and found that out of 75 patients, who underwent EDCR, 31 patients had nasal Table 1. showing preoperative nasal pathology

\begin{tabular}{|l|l|l|}
\hline Nasal pathology & No of patients & Percentage \\
\hline Deviated nasal septum(DNS) & 20 & 26.6 \\
\hline Concha bullosa & 5 & 6.6 \\
\hline Chronic Rhinosinusitis & 5 & 6.6 \\
\hline Nasal polyps & 1 & 1.4 \\
\hline Total No. of Pts & 31 & 41.2 \\
\hline
\end{tabular}




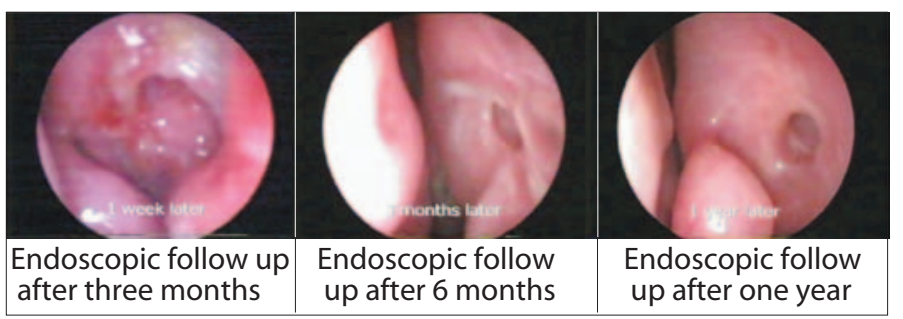

pathology which is mentioned in table 1 .

Out of 20 DNS patients, only 8 patients with high DNS needed correction therapy and one patient of nasal polyp needed FESS which was done at the same sitting.

Age of the patients ranged from $18 \mathrm{yrs}$ to $60 \mathrm{yrs}$. Out of 75 patients, 35 were male and 40 were female. All 75 patients came for follow up regularly after one week, 3 months, 6 months and one year respectively as per our instruction. There were no major complications noted during surgery or in post operative period of EDCR. Minor complications noted were mentioned in table2.

\begin{tabular}{|l|l|l|l|}
\hline Table 2. & showing the complications during follow up after EDCR \\
\hline Serial & No complications & No of patient & spercentage \\
\hline 1. & Recurrence of epiphora & 7 & 9.3 \\
2. & Granuloma formation & 3 & 4.0 \\
\hline 3. & Synechiae formation & 5 & 6.6
\end{tabular}

Out of seven patients, two had upper lacrimal pathway obstruction and were referred to ophthalmologist. In remaining in five patients' cause of recurrence of epiphora could not be found out. Among these five patients two patients underwent revision EDCR and three patients wanted to wait and later lost to follow up. Three patients, who had granuloma formation at the site of sac opening, needed endoscopic excision of granuloma. Synechiae formation was noted in five patients, which was released endoscopically.

\section{DISCUSSION:}

Chronic dacryocystitis is one of the commonest causes of epiphora. External DCR was the standard surgical procedure for most of the years in 20th century, but external DCR has failure rate ranging from $3-15 \% .6$ After the advances in the nasal endoscopic surgery, EDCR has gained popularity. EDCR has many advantages like avoids external scar, preserves pumping action of orbicularis oculi muscle, can be performed during active phase of infection of the lacrimal sac, which is a relative contraindication for external DCR.4,5,7,8 We found that it was not necessary to use silicon tube in all cases of EDCR, similar results were shown in other studies too.9,10 Umer et al performed 256 EDCR from 1994 to 2002, out of which 55 cases (21.5\%) required additional endonasal procedure. 11 Devi Prasad et al found that out of 24 patients six patients had concomitant nasal pathology which needed endonasal procedure. 12 In our study, out of 75 patients 31 patients(41.3\%) had other nasal pathology, some of which needed correction. Ramkrishnan et al performed 27 EDCR in 20 patients from 2003 to 2006, where they claimed $100 \%$ success rate for anatomic patency and 93\% for complete resolution of epiphora. ${ }^{1}$ Devi Prasad et al found success rate of $90 \%$ in control of epiphora. 12 In our study, we found success rate of (80.\%) in control of epiphora.

In another unpublished study, done in the Dept. of Otorhinolaryngology and Ophthalmology at TU-Teaching Hospital, to compare the EDCR with that of external DCR, it was found that in EDCR out of 27 patients duct were found to be patent in 24 , where as in external DCR group out of 32 patients, duct were found to be patent in 29 patients. The conclusion was that the success rate of EDCR is comparable to that of external DCR. There are other studies which show the similar results. $14,15,16$

\section{CONCLUSION:}

For the success of EDCR, proper selection of patient is very important. Correction of nasal pathology like DNS, CRS, nasal polyps etc. should be done either before or during the surgery to increase the success rate .Post operative follow up with nasal endoscopy is mandatory to remove the blood clots, to release the synechiae and to remove the granuloma if present. In conclusion, EDCR is simple, safe and effective method to treat chronic dacryocystitis with above mentioned advantages, it can be a better alternative for external DCR.

\section{REFERENCES:}

1. Tsirbas A, Davis G, Wormald PJ (2005) Revision dacryocystorhinostomy: a comparision of endoscopic and external techniques. Am J Rhinol 19(3):322-325.

2. Caldwill G (1893) Two new operations for obstruction of the nasal duct, with preservation of the canaliculi,and with an incidental description of a new lacrimal probe.Am J Ophthalmol 10;189- 193

3. Mc Donogh and Meiring JH. (1989) Endoscopic transaction DCR. J.Laryngolotol 103(6); $585-587$

4. Eloy P, Bertrand B, Martinoz M, Hoebeke M, Watelet JB, Jamart (1995) Endoscopic DCR indications, techniques and results. Rhinology Dec.33(4)229-233

5. Muscatello L, GiudiceM, SprianoG, Tondini L(2005). Endoscopic dacryocystorhinostomy : personal experience.Acta Otorhinolaryngol Ital 25(4);209-213

6. Metson R (1990) The endoscopic approach for revision DCR. Laryngoscope 106;187-189

7. Mantynen J, Yoshitsugu M, Rautianinen m (1997): Results of dacryocystorhinostomy in 96 patients. Acta Otolaryngol suppl 529:187-189.

8. Sprekelsen MB, Barberan MT (1996) Endoscopic dacryocystorhinostomy: Surgical technique and results. Laryngoscope 106: $187-189$.

9. Liu D, Bosley TM (2003) Silicon nasolacrimal intubation with mitomycin-C : A prospective, randomized, double- masked study.Ophthalmology 110(2):306-310.

10. Smirnov G,Tuomilehto H, Terasvirta M, Nuutinen J,Seppa J (2006) Silicon tubing after endoscopic dacryocystorhinostomy: is it necessary? Am J Rhinol 20(6):600-602.

11. Umer MN, Schreiber S, Yung MW (2007) Concomitant nasal procedure in endoscopic dacryocystorhinostomy.J Laryngol Otol 121(12):1170-1176.

12. Deviprasad D, Mahesh S.G, Pujary k, Pillai S, Mallick S.A, Jain V (2009) Endonasal endoscopic dacryocystorhinostomy: our experience. Indian J Otolaryngol head Neck surg 61:223-226.

13. Ramakrishnan VR, Hink EM, Durairaj VD, Kingdom TT(2007) Outcome after endoscopic dacryocystorhinostomy without mucosal flap preservation.Am J Rhinol 21: 753-757

14. Trimarchi M,Resti A G,Bellini C,Forti M, Bussi M (2009) Anastomosis of nasal mucosal and lacrimal sac flaps in endoscopic dacryocystorhinostomy . Eur Arch Otorhinolaryngol 266:17471752.

15. Hartikainen J, Antila J, Varpula M, Puukka P,Seppa H, Grenman R (1998) Prospective randomized comparision of endonasal endoscopic dacryocystorhinostomy and external DCR. Laryngoscope 108(12):1861-1866.

16. DolmanPJ(2003) Comparision of external dacryocystorhinostomy with nonlaser endonasal dacryocystorhinostomy. Ophthalmology.110(1):78-84. 